\title{
EKSPLORASI POTENSI DESA SUKAMENAK UNTUK KETAHANAN PANGAN KELUARGA DI MASA PANDEMIK COVID-19
}

\author{
Eneng Nunuz Rohmatullayaly, Budi Irawan, dan Johan Iskandar \\ Departemen Biologi, Fakultas Matematika dan Ilmu Pengetahuan Alam, Universitas Padjadjaran \\ Email: e.n.rohmatullayaly@unpad.ac.id
}

\begin{abstract}
ABSTRAK. Ketahanan pangan merujuk pada keadaan dimana semua orang memiliki akses secara fisik, sosial, dan ekonomi terhadap makanan yang meliputi aspek ketersediaan, aksesibilitas, pemanfaatan, dan stabilitas. Saat ini, pandemi Covid-19 menjadi ancaman serius bagi ketahanan pangan dan telah menambah angka kekurangan gizi penduduk. Tanpa pengetahuan yang cukup, masyarakat akan kesulitan memenuhi kebutuhan pangan keluarga. Oleh karena itu, kegiatan penelitian dan pengabdian pada masyarakat (PPM) ini dilakukan dengan metode kualitatif (wawancara dan observasi) guna mengekplorasi potensi desa termasuk sumber daya alamnya, serta sosialisasi untuk penyadartahuan dan pemberdayaan masyarakat baik petani berskala kecil maupun ibu rumah tangga. Masyarakat Desa Sukamenak dahulunya bermata pencaharian sebagai petani, becocok tanaman padi (Oryza sativa) dan tembakau (Nicotiana tabacum). Namun saat ini, masyarakat lebih banyak bekerja sebagai buruh tani di luar desa seiring keterbatasan lahan yang mereka miliki, dikarenakan adanya alih fungsi lahan menjadi Waduk Jatigede. Masyarakat juga mulai beralih ke sektor pariwisata dengan menyediakan jasa sewa perahu rakit untuk memancing ikan di Waduk Jatigede. Ada lima sektor teridentifikasi baik kondisi dan potensinya, yaitu pertanian, peternakan, perikanan, pariwisata, serta perdagangan dan lainnya yang dapat dikembangkan dalam skala rumah tangga. Kelima potensi ini disosialisasikan kepada pemerintah desa dan masyarakat dalam bentuk artikel popular dan infografis mengingat adanya aturan physical/social distancing selama pandemi.
\end{abstract}

Kata kunci: Desa Sukamenak; ketahanan pangan; pandemi Covid-19

ABSTRACT. Food security refers to a condition in which all people have physical, social, and economic access to food which includes aspects of availability, accessibility, utilization, and stability. Currently, Covid-19 pandemic is a serious threat to food security and has increased the number of malnutrition. Without sufficient knowledge, people will find it difficult to supply family food needs. Therefore, Research dan community service activities are carried out using qualitative methods (interviews and observations) to explore the potential of the village including its natural resources, as well as socialization for community awareness and empowerment, both small-scale farmers and housewives. In the past, the Sukamenak Village community lived as farmers, who cultivated rice (Oryza sativa) and tobacco (Nicotiana tabacum). However, because of the change in land use to Waduk Jatigede, currently, the community mostly works as agricultural laborers outside the village. The community has also started to switch to the tourism sector by providing raft boat rental services for fishing in Waduk Jatigede. There are five identified sectors with both conditions and potential, namely agriculture, livestock, fisheries, tourism, and trade, and others that can be developed at a household scale. These five potentials were disseminated to the rural government and community in the form of popular articles and infographics considering the existence of physical/ social distancing rules during the pandemic.

Keywords: Sukamenak Village; food security; Covid-19 pandemic

\section{PENDAHULUAN}

Berdasarkan World Food Summit tahun 1996, ketahanan pangan merujuk pada keadaan di mana semua orang memiliki akses secara fisik, sosial, dan ekonomi terhadap pangan untuk memenuhi kebutuhan hidup sehari-hari dalam jumlah serta kualitas yang cukup, aman untuk dikonsumsi, dan bergizi. Ketahanan pangan ini meliputi aspek ketersediaan (availability), aksesibilitas (accessibility), pemanfaatan (utilization), dan stabilitas (stability) yang erat kaitannya dengan kondisi kesehatan seseorang ataupun masyarakat (FAO, 2006). Tanpa ketahanan pangan yang baik, sulit bagi suatu negara untuk menghasilkan Sumber Daya Manusia (SDM) bermutu dalam mendukung keberhasilan pembangunan. Oleh karena itu, hal ini juga menjadi salah satu fokus pembangunan secara berkelanjutan/ sustainable development goals (SDGs) yang digagas oleh Perserikatan Bangsa Bangsa (PBB), yaitu tanpa kelaparan (Zero Hunger). Kondisi kelaparan ditargetkan akan berakhir di tahun 2030 dengan memastikan semua orang dapat mengakses makanan yang bergizi (UN, 2015).

Permasalahan yang dihadapi dalam mewujudkan ketahanan pangan diantaranya perubahan iklim global, kerusakan lingkungan (Schmidhuber dan Tubiello, 2007; Altieri dan Nicholls, 2013; Fowler dan Westengen, 2019), dan alih fungsi lahan (UN, 2015) yang berimbas pada ketersediaan pasokan pangan. Kondisi tersebut juga berdampak pada ketidakmampuan masyarakat untuk memenuhi pangan ditingkat wilayah maupun rumah tangga (kerawanan pangan). Kerawanan pangan dapat terjadi secara berulang pada masa tertentu (kronis) maupun dalam keadaan darurat seperti bencana (transien) (DKP, 2006). Saat ini, pandemi Covid-19 menjadi bencana global yang mengubah berbagai tatanan 
kehidupan manusia dan berimbas kepada kondisi ekonomi, pangan, kesehatan, dan gizi. Kondisi ini menjadi ancaman serius bagi ketahanan pangan dan telah menambah angka kekurangan gizi pada tahun 2020, yaitu antara 83 dan 132 juta orang dari kondisi sebelumnya (FAO et al., 2020). Selain itu, kondisi ini juga berimbas pada ekonomi keluarga, sehingga ketahanan pangan pada level keluarga pun menjadi masalah baru yang menjadi perhatian.

Dampak perubahan ekonomi akan berimbas pada kemampuan masyarakat untuk mengakses pangan baik secara kuantitas maupun kualitas. Kondisi ini juga menciptakan lingkaran setan (vicious circle), di mana kualitas makanan yang dikonsumsi yang kurang baik meningkatkan berbagai tipe malnutrisi dan penyakit. Kondisi yang tidak sehat ini akan menurunkan produktifitas dan meningkatkan kemiskinan yang kemudian berimbas pada ketidakmampuan mengakses pangan bergizi (Schmidhuber dan Tubiello, 2007; FAO et al., 2020) dan begitu seterusnya siklus ini berjalan. Sehingga tanpa kesiapan dan pengetahuan yang cukup, masyarakat akan kesulitan memenuhi kebutuhan pangan keluarga.

Terdapat berbagai pendekatan yang dapat ditempuh sebagai solusi (Altieri, 2004; DKP, 2006; FAO, 2006; Altieri dan Nicholls, 2013; UN, 2015; Ariningsih dan Rachman, 2016; Phungpracha et al., 2016; Patel et al. 2020), beberapa diantaranya adalah memperbaiki kondisi pangan desa dengan memanfaatkan sumber daya lokal dan keanekaragaman hayati, pengetahuan lokal atau tradisional (Traditional ecological knowledge/TEK), dan pemberdayaan masyarakat baik petani berskala kecil maupun ibu rumah tangga agar dapat mewujudkan lumbung pangan masyarakat. Menurut Phungpracha et al., (2016), ketahanan pangan di Thailand dapat ditingkatkan dan mampu beradaptasi dengan perubahan lingkungan dan sosial ekonomi dengan menerapkan TEK. Selain itu, penerapan pertanian tradisional di India menciptakan kondisi pangan dan lingkungan yang berkelanjutan (Patel et al. 2020). Untuk dapat melakukan pemberdayaan secara tepat, maka perlu dilakukan eksplorasi potensi desa termasuk sumber daya alam yang kedepannya dapat dikembangkan sebagai upaya meningkatkan kemampuan ekonomi masyarakat (daya beli) dalam mengakses pangan yang beragam.

Desa Sukamenak berada di Kecamatan Darmaraja, Kabupaten Sumedang, Provinsi Jawa Barat terdiri dari Dusun Munjul dan Pasir Lempah. Luas wilayah Desa Sukamenak yaitu 40 hektar dan berbatasan langsung dengan Waduk Jatigede. Secara tofografi desa ini berada pada ketinggian antara 130$280 \mathrm{~m}$ dpl (meter di atas permukaan laut) dengan kemiringan sekitar 20-45 . Survey tahun 2018 mendokumentasikan bahwa jumlah penduduk Desa Sukamenak sebanyak 1650 orang, terdiri dari $550 \mathrm{KK}$ (Kepala Keluarga) (Profil Desa Sukamenak, 2020). Alih fungsi lahan pertanian saat pembangunan Waduk Jatigede, mengakibatkan sektor pertanian bukan lagi sebagai mata pencaharian yang utama penduduknya. Masyarakat pun mulai beralih ke sektor pariwisata sebagai sumber ekonomi, seperti menyediakan jasa perahu untuk memancing di Waduk Jatigede. Kondisi pandemi Covid-19, tentunya juga berdampak pada perekonomian penduduk. Oleh karena itu, tujuan dari kegiatan penelitian dan pengabdian pada masyarkat (PPM) ini adalah untuk menggali potensi desa guna mendukung ketahanan pangan Desa Sukamenak khususnya saat pandemi Covid-19 sehingga dapat dimanfaatkan secara maksimal dan bernilai ekonomi, serta nantinya dapat meningkatkan taraf hidup masyarakat di Desa Sukamenak.

Pandemi Covid-19 yang oleh pemerintah ditetapkan sebagai bencana global memaksa berbagai kegiatan dilakukan secara daring, tidak terkecuali kegiatan penelitian dan pengabdian pada masyarakat (PPM). Kegiatan PPM ini terintegrasi dengan Kegiatan Kuliah Kerja Nyata (KKN) Mahasiswa dari berbagai program studi yang dilaksanakan pada 1 sampai 31 Juli 2020 di Desa Sukamenak, Kecamatan Darmaraja, Kabupaten Sumedang, Jawa Barat.

\section{METODE}

Metode yang digunakan adalah metode kualitatif dengan teknik pengumpulan data dengan melakukan wawancara dan observasi. Wawancara dilakukan melalui daring menggunakan media video conference (Google Meet dan Zoom), media komunikasi (Whatsapp dan Line), serta observasi berupa kunjungan ke lokasi yang disesuaikan dengan kondisi dan kebutuhan dengan menerapkan standar protokol kesehatan. Adapun tahapan pelaksanaan dengan rincian sebagai berikut:

\section{Penelusuran Informasi}

Informasi mengenai potensi Desa Sukamenak dilakukan dengan wawancara yang dilakukan secara daring. Wawancara dilakukan terhadap beberapa informan/narasumber seperti, Kepala Desa Sukamenak dan perangkat desa lainnya, seperti Kepala Dusun (Kadus); warga yang dituakan (kokolot desa); para petani, dan pedagang di desa. Selain itu, untuk mendapatkan gambaran dan dokumentasi desa secara konkret, dilakukan observasi lapangan dengan menerapkan standar protokol kesehatan. Observasi dilakukan untuk mengetahui gambaran umum tentang lingkungan desa, seperti kondisi perkampungan, macam-macam pertanian, dan kondisi Waduk Jatigede.

\section{Pembuatan Artikel dan Infografis}

Informasi dan data-data yang diperoleh 
mengenai potensi sumber daya alam yang dapat dikembangkan di Desa Sukamenak, kemudian diakukan uji silang (cross-checking), dirangkum, dianalisis (Newing et al., 2011), dan disusun dalam bentuk artikel popular dan infografis untuk dapat disosialisasikan.

\section{Sosialisasi Potensi Desa}

Artikel popular dan infografis menjadi media informasi dalam mensosialisasikan potensi Desa Sukamenak bagi pemerintah desa dan masyarakat, maupun menjadi media promosi kepada masyarakat luas. Sosialisasi dilakukan dengan menyerahkan artikel dan infografis tersebut kepada pemerintah Desa Sukamenak.

\section{HASIL DAN PEMBAHASAN}

\section{A. Kondisi dan Potensi Desa}

Masyarakat Desa Sukamenak dulunya memiliki mata pencaharian sebagai petani, becocok tanaman padi (Oryza sativa) dan tembakau (Nicotiana tabacum). Selain itu, ada juga yang beternak dan mengelola hasilnya untuk diperjual belikan. Kondisi tersebut berubah seiring adanya perubahan fungsi lahan yang terjadi di Desa Sukamenak. Terdapat lima sektor yang teridentifikasi kondisi dan potensinya di Desa Sukamenak selama kegiatan ini (Tabel 1).

Saat ini, masyarakat lebih banyak bekerja sebagai buruh tani di luar desa seiring keterbatasan lahan yang mereka miliki. Hanya terdapat tiga belas kelompok tani dan empat kelompok tani wanita di Desa Sukamenak. Akan tetapi, hasil panen mereka tidak lagi mencukupi kebutuhan seharihari, sehingga masyarakat harus membelinya dan menjadi tergantung pada pasar. Selain itu, untuk mengairi lahan pertanian yang tersisa, para petani hanya mengandalkan air dari Waduk Jatigede yang kondisinya pun terkadang mengalami kekeringan dimusim kemarau.

Sementara itu, masalah utama dari sektor peternakan terletak pada keterbatasan variasi ternak yang dibudidayakan oleh masyarakat, yang mayoritas beternak Bebek. Masyarakat pun hanya langsung memanfaatkan ternak untuk memasok daging, bukan produk turunan lain seperti telur. Sementara dari sektor perikanan, masyarakat juga belum menerapkan sistem menanam benih ikan secara berkala untuk keberlangsungan ketersediaan ikan di Waduk Jatigede. Adanya invasif spesies seperti ikan sapusapu (Pterygoplichthys sp.) yang justru tidak dapat dikonsumsi menambah buruk kondisi hasil tangkapan ditambah dengan kualitas dari alat-alat tangkap ikan yang kurang mumpuni. Masalah lain pun hadir ketika debit air di Waduk Jatigede menurun. Selain berimbas pada kehidupan ikan yang berada di sana, sektor pariwisata pun menjadi meredup.

Meskipun masih bersifat musiman dan bergantung pada debit air, pariwisata menjadi sektor yang dilirik masyarakat pasca pembangunan Waduk Jatigede. Masyarakat memanfaatkan waduk untuk memancing ikan menggunakan perahu rakit, sehingga tersedialah jasa penyewaannya. Selain itu, wisatawan yang cukup banyak menciptakan peluang usaha dengan membuka warung-warung makanan di atas perahu rakit (Gambar 1).

Dari berbagai kondisi yang dapat dieksplorasi, ada beberapa potensi yang dapat dikembangkan untuk mendukung ketahanan pangan keluarga (Tabel 1). Beberapa diantaranya dapat direalisasikan di masa pandemi Covid-19, yaitu 1). Berkebun di polybag di area rumah atau pekarangan sebagai sumber pasokan pangan keluarga, 2). Mengolah limbah rumah tangga menjadi pupuk kompos untuk menekan biaya pertanian, 3). Menyemai benih ikan di Waduk Jatigede. Kegiatan-kegiatan ini dapat dilakukan dalam skala keluarga dan tidak membutuhkan modal yang tinggi. Selain itu, masyarakat juga tetap dapat melakukan physical/social distancing (jaga jarak) untuk menghindari penularan Covid-19.

Lahan sekitar rumah atau sering disebut pekarangan berpotensi menjadi agroekosistem yang

Tabel 1. Gambaran kondisi dan potensi yang dapat dikembangkan di Desa Sukamenak

\begin{tabular}{|c|c|c|c|}
\hline No. & Sektor & Kondisi & Potensi \\
\hline 1. & Pertanian & $\begin{array}{l}\text { - Lahan terbatas } \\
\text { - Tidak memiliki sistem irigasi } \\
\text { - Hasil panen tidak mencukupi kebutuhan } \\
\text { sehari-hari }\end{array}$ & $\begin{array}{l}\text { - Berkebun di Polybag di area rumah, sebagai pasokan } \\
\text { pangan keluarga } \\
\text { - Pembuatan pupuk kompos untuk menekan biaya } \\
\text { pertanian }\end{array}$ \\
\hline 2. & Peternakan & $\begin{array}{l}\text { - Terbatasnya variasi ternak } \\
\text { - Pemanfaatan hanya berupa daging }\end{array}$ & $\begin{array}{l}\text { - Budidaya lebah tanpa sengat } \\
\text { - Budidaya unggas petelur }\end{array}$ \\
\hline 3. & Perikanan & $\begin{array}{l}\text { - Belum memiliki sistem pengelolaan } \\
\text { - Adanya invasif spesies berupa ikan sapu-sapu } \\
\text { - Debit air yang tidak stabil }\end{array}$ & $\begin{array}{l}\text { Membuat siklus penyemaian benih ikan di Waduk } \\
\text { Jatigede, agar ketersediaan ikan tetap terjaga dan wisata } \\
\text { memancing terus berjalan }\end{array}$ \\
\hline 4. & Pariwisata & - Belum memiliki sistem pengelolaan wisata & $\begin{array}{l}\text { - Membuat siklus penyemaian benih ikan di Waduk } \\
\text { Jatigede, agar ketersediaan ikan tetap terjaga dan wisata } \\
\text { memancing terus berjalan } \\
\text { - Membuat sistem pengelolaan dan promosi potensi wisata }\end{array}$ \\
\hline 5. & $\begin{array}{l}\text { Perdagangan dan } \\
\text { lainnya }\end{array}$ & $\begin{array}{l}\text { - Perdagangan produk olahan, seperti kripik } \\
\text { pisang, pepes ikan, dan kerajinan rumah } \\
\text { tangga lainnya }\end{array}$ & $\begin{array}{l}\text { - Membuat sistem pengelolaan, branding, dan promosi } \\
\text { untuk mendapat pasar yang besar }\end{array}$ \\
\hline
\end{tabular}


menyediakan sumber gizi keluarga (Iskandar \& Iskandar, 2016), apotek hidup dengan menyediakan tanaman obat (Suryana \& Iskandar, 2013; Kadarsah \& Susilawati, 2018), dan konservasi keanekaragaman hayati (Njurumana, 2016). Menurut Swardana (2020), optimasi lahan pekarangan ini cocok dilakukan saat pandemik Covid-19 dengan mengikuti konsep Kawasan Rumah Pangan Lestari (KRPL) yang digagas oleh Kementrian Pertanian, dengan berbagai tipe budidaya, salah satunya dengan menanam sayuran di polybag.

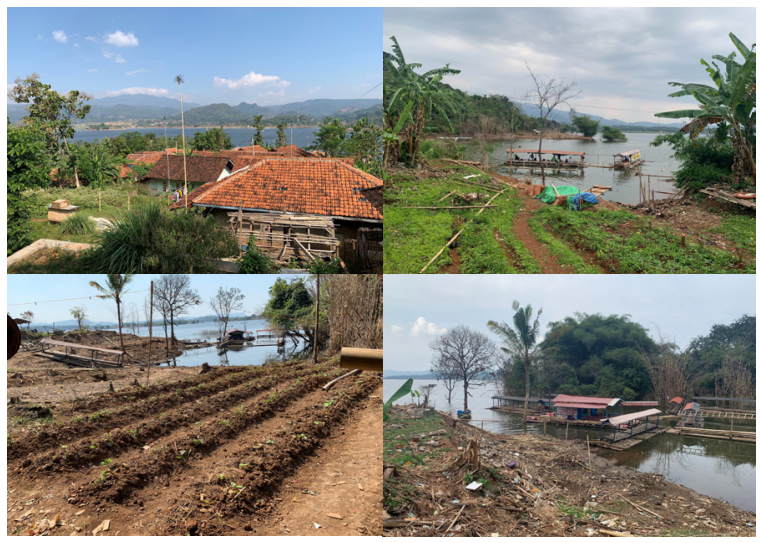

Gambar 1. Kondisi Desa Sukamenak; a. pemukiman penduduk, b-c. lahan pertanian dan Waduk Jatigede, d. rakit-rakit dan area untuk memancing

\section{B. Artikel Popular dan Infografis}

Artikel popular disusun guna menjadi media komunikasi dan juga menjadi dasar dalam pembuatan infografis. Infografis merupakan suatu bentuk penyajian data dan informasi penting dengan konsep visual yang terdiri dari teks dan ilustrasi yang menarik agar dapat lebih mudah dipahami dan efektif dan sangat cocok dengan gaya hidup era digital. Infografis dinilai menjadi cara termudah untuk merangkum semua informasi penting menjadi singkat dan padat serta dapat meningkatkan minat membaca dan meningkatkan rasa keingintahuan (Siricharoen, 2013; Saptodewo, 2014).

Potensi-potensi Desa Sukamenak yang berhasil dieksplorasi divisualisasikan dalam bentuk infografis sebagai media informasi bagi pemerintah desa maupun masyarakat setempat guna meningkatkan kesadaran dan wawasan masyarakat akan potensi yang ada dengan lebih efektif dan cepat. Selain itu, penyebar luasan informasi pun dapat menggunakan media komunikasi dan sosial yang lebih beragam, mengingat adanya physical/social distancing. Beberapa contoh infografis dalam penyajian informasi kali ini dapat dilihat pada Gambar 2.

\section{Kegiatan Sosialisasi}

Beberapa potensi desa yang berhasil dieksplorasi yaitu adanya potensi memaksimumkan lahan pekarangan dengan penggunaan polybag untuk menghasilkan tanaman pangan guna menyiasati lahan yang terbatas, pengolahan limbah ternak untuk pupuk, budidaya lebah tak bersengat, peternakan dan perikanan dengan sistem pengelolaan yang lebih baik, serta adanya potensi wisata memancing dengan perahu rakit di sekitar Waduk Jatigede (Tabel 1). Potensi-potensi tersebut disajikan dalam bentuk artikel popular dan infografis yang diserahkan kepada pemerintah desa untuk menjadi media sosialisasi kepada masyarakat (Gambar 2).
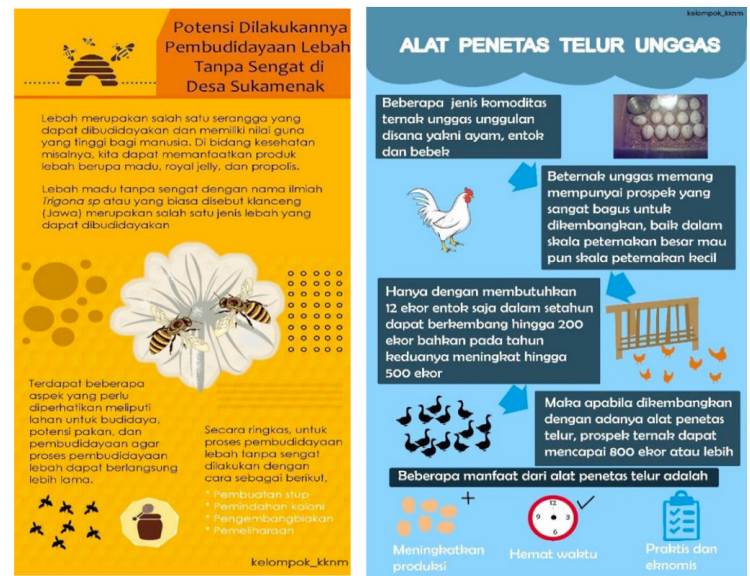

Gambar 2. Contoh infografis potensi Desa Sukamenak yang dapat dikembangkan

Menurut Dewan Ketahanan Pangan (2006), ketahanan pangan akan terwujud dengan meningkatkan keterlibatan pemerintah, swasta, dan masyarakat. Sehingga, direkomendasikan juga agar desa mengajukan pembuatan website resmi sebagai media alternatif untuk penyebar luasan informasi potensi desa tersebut ke publik terutama instansi pemerintah dan swasta (stakeholder) lainnya untuk kelak dapat dikembangkan. Adanya official website juga diharapkan dapat meningkatkan potensi pariwisata yang akan menjadi sumber ekonomi masyarakat yang pada akhirnya berimbas pada kemampuan masyarakat mengakses pangan yang lebih baik.

\section{SIMPULAN}

Kegiatan PPM ini berhasil menggali berbagai potensi Desa Sukamenak mulai dari sektor pertanian hingga pariwisata dan memberikan alternatif solusi untuk masyarakatnya. Potensi dan alternatif solusi tersebut disosialisasikan dalam bentuk artikel popular dan infografis agar mudah dipahami dan efektif terutama saat pandemi Covid-19. Keberadaan informasi dan alternatif solusi yang tersosialisasikan kepada pemerintah desa dan masyarakat nantinya dapat dikembangkan ketahapan berikutnya berupa pembimbingan, pelatihan, dan pembedayaan masyarakat lainnya. Selain itu, untuk menghubungkan masyarakat Desa Sukamenak dengan publik baik 
masyarakat dan pemerintah di luar desa serta stakeholder lainnya, direkomendasikan agar desa membuat official website yang dapat diajukan kepada kementrian desa. Sehingga artikel-artikel popular dan infografis yang telah dihasilkan pun dapat dimuat pada official website.

\section{UCAPAN TERIMA KASIH}

Terima kasih kami ucapkan kepada pemerintah dan masyarakat Desa Sukemenak, serta mahasiswa KKN Integratif tahun 2020 yang telah menjadi bagian dari pelaksanaan Pengabdian Kepada Masyarakat ini. Kegiatan pengabdian ini didanai dari Hibah Internal Universitas Padjadjaran Tahun 2020. Selain itu, kami ucapkan terima kasih kepada Dr. Ruhyat Partasasmita, M.Si (almarhum) yang telah membantu dalam pelaksanaan kegiatan ini.

\section{DAFTAR PUSTAKA}

Altieri M. A. \& Nicholls, C. I. (2013). The adaptation and mitigation potential of traditional agriculture in a changing climate. Special Issue on "Climate Change Mitigation and Adaptation with Local Communities and Indigenous Peoples". DOI 10.1007/s10584-013-0909-y.

Altieri, M. A. (2004). Linking ecologists and traditional farmers in the search for sustainable agriculture. Frontiers in Ecology and the Environment, 2(1), 35-42.

Ariningsih, E., \& Rachman, H. P. (2016). Strategi peningkatan ketahanan pangan rumah tangga rawan pangan. Analisis Kebijakan Pertanian, 6(3), 239-255.

Dewan Ketahanan Pangan (DKP). (2006). Kebijakan Umum Ketahanan Pangan 2006-2009. Jurnal Gizi dan Pangan, 1(1), 57-63.

FAO, IFAD, UNICEF, WFP, \& WHO. (2020). The State of Food Security and Nutrition in the World 2020. Transforming food systems for affordable healthy diets. Rome, FAO. https://doi.org/10.4060/ca9692en.

Food and Agriculture Organization (FAO). (2006). Food Security. Policy Brief, 2, 1-4.

Fowler, C., \& Westengen, O.T. (2019). Climate Change, Food, and Biodiversity. dalam Lovejoy, T.E., Hannah, L. (eds), Biodiversity and Climate Change: Transforming the Biosphere. Yale University Press, New Haven \& London, pp. 347355.

Iskandar, J., \& Iskandar, B., S. (2016). Etnoekologi dan Pengelolaan Agroekosistem oleh Penduduk Desa Karangwangi Kecamatan Cidaun, Cianjur Selatan Jawa Barat. Jurnal Biodjati 1(1), 1-12.
Kadarsah, A., \& Susilawati, I., O. (2018). Kajian Perbandingan Luas Pekarangan Dan Kearifan Lokal Jenis Tanaman Obat Di Pesisir Pantai Kabupaten Tanah Laut. Jurnal Biodjati 3 (1), 36-46.

Newing, H., Eagle, C.M., Puri, R.K., Watson, C.W. (2011). Conducting Research in Conservation: A Social Science Perspective. Routledge, London and New York.

Njurumana, G. N. (2016). Masyarakat desa dan manajemen biodiversitas flora pada sistem pekarangan di Kabupaten Sumba Tengah. Jurnal Penelitian Kehutanan Wallacea, 5(1), 25-36.

Patel, S. K., Sharma, A., \& Singh, G. S. (2020). Traditional agricultural practices in India: an approach for environmental sustainability and food security. Energy, Ecology and Environment, 5(4), 253-271.

Phungpracha, E., Kansuntisukmongkon, K., \& Panya, O. (2016). Traditional ecological knowledge in Thailand: Mechanisms and contributions to food security. Kasetsart Journal of Social Sciences, 37(2), 82-87.

Profil Desa Sukamenak. (2020). Profil Desa Sukamendak (tidak dipublikasikan).

Saptodewo, F. (2014). Desain infografis sebagai penyajian data menarik. Jurnal Desain 1(3), 163-218.

Schmidhuber, J., \& Tubiello, F. N. (2007). Global food security under climate change. Proceedings of the National Academy of Sciences, 104(50), 19703-19708.

Siricharoen, W. V. (2013, May). Infographics: the new communication tools in digital age. In The international conference on e-technologies and business on the web (ebw2013) (pp. 169-174).

Suryana, Y., \& Iskandar J. (2013). Studi Pengetahuan Lokal Tanaman Obat Pada Agroekosistem Pekarangan Dan Dinamika Perubahannya Di Desa Cibunar Kecamatan Rancakalong Kabupaten Sumedang-jawa Barat. BionaturaJurnal Ilmu-ilmu Hayati dan Fisik 15(3), 203209.

Swardana, A. (2020). Optimalisasi Lahan Pekarangan Sebagai Salah Satu Upaya Pencegahan Krisis Pangan di Masa Pandemi Covid-19. Jagros: Jurnal Agroteknologi dan Sains (Journal of Agrotechnology Science), 4(2), 246-258.

United Nation (UN). (2015). Agenda for Sustainable Development. Diakses dari https://sdgs.un.org/ publications/transforming-our-world-2030agenda-sustainable-development-17981. 